\title{
Radioimmunotherapy of infectious diseases
}

\author{
Ekaterina Dadachova, $\mathbf{P h D}{ }^{1,2,{ }^{*}}$ and Arturo Casadevall, $\mathbf{M D}, \mathbf{P h D}^{2,3}$ \\ 1 Department of Nuclear Medicine, Albert Einstein College of Medicine of Yeshiva University, Bronx, NY, \\ 10461 USA
}

2 Departments of Microbiology and Immunology, Albert Einstein College of Medicine of Yeshiva University, Bronx, NY, 10461 USA

3 Department of Medicine, Albert Einstein College of Medicine of Yeshiva University, Bronx, NY, 10461 USA

\begin{abstract}
The need for novel approaches to treat infectious diseases is obvious and urgent. This situation has renewed interest in using monoclonal antibodies (mAbs) in therapy of infectious diseases. During the last 5 years radioimmunotherapy (RIT), a modality developed for cancer treatment, has been successfully adapted for the treatment of experimental fungal (C. neoformans and H. capsulatum), bacterial (S. pneumoniae and B. anthracis) and viral (HIV-1) infections. RIT produced none or only transient hematological toxicity in experimental animals. Investigation of radiobiological mechanisms of RIT of infections showed that microbial cells are killed by both "direct hit" and "crossfire" radiation. MAbs radiolabeled with either alpha- or beta-emitters stimulated apoptosis-like cell death, while only mAbs radiolabeled with alpha-emitter ${ }^{213} \mathrm{Bi}$ also decreased the metabolic activity of microbial cells. The success of this approach in laboratory studies combined with earlier nuclear medicine experience on pre-clinical and clinical studies utilizing radiolabeled organism-specific antibodies for imaging of infections provides encouragement for feasibility of therapeutically targeting microbes with labeled antibodies. We envision that first the organism-specific mAbs will be radiolabeled with imaging radionuclides such as ${ }^{99 \mathrm{~m}} \mathrm{Tc}$ or ${ }^{111} \mathrm{In}$ to localize the sites of infection with SPECT followed by RIT with ${ }^{188} \mathrm{Re}$ - or ${ }^{90} \mathrm{Y}$-labeled mAb, respectively. Also, immunoPET might be utilized for imaging of infection before treatment if such positron-emitting radionuclides as ${ }^{86} \mathrm{Y}$ (matching pair for ${ }^{90} \mathrm{Y}$ ) or ${ }^{124} \mathrm{I}$ (matching pair for ${ }^{131} \mathrm{I}$ ) are available. It might be possible to create a so-called "pan-antibody" which would recognize an antigen shared by a particular class of human pathogens such as fungi, for example. The availability of such antibodies would eliminate the necessity of having antibodies specific for each particular microorganism and would enormously enhance the development of RIT of infectious diseases.
\end{abstract}

\section{INRODUCTION}

The need for novel approaches to treat infectious diseases is obvious and urgent. Currently available antibiotics have become less effective as microbes are increasingly developing resistance. In recent decades the problem has been compounded by the emergence of many new infectious diseases like HIV. Simultaneously the population of patients in whom current antimicrobial therapies are not effective because of their low immune status is expanding and

\footnotetext{
*Author for correspondence: Department of Nuclear Medicine, 1695A Eastchester Road, Bronx, NY 10461 USA, Ph: 718-405-8485; FAX: 718-405-8457; E-mail: E-mail: edadacho@ aecom.yu.edu.

Publisher's Disclaimer: This is a PDF file of an unedited manuscript that has been accepted for publication. As a service to our customers we are providing this early version of the manuscript. The manuscript will undergo copyediting, typesetting, and review of the resulting proof before it is published in its final citable form. Please note that during the production process errors may be discovered which could affect the content, and all legal disclaimers that apply to the journal pertain.
} 
these include HIV-infected individuals, cancer patients undergoing chemotherapy and recipients of organ transplants. In addition, there is a threat of biological agents specifically engineered to be lethal even in immunocompetent population.

This situation has renewed interest in using monoclonal antibodies (mAbs) in therapy of infectious diseases (1). During the last 5 years radioimmunotherapy (RIT), a modality developed for cancer treatment, has been successfully adapted for the treatment of experimental fungal, bacterial and viral infections (2-6). The success of this approach in laboratory studies combined with earlier nuclear medicine experience on pre-clinical and clinical studies showing the utility of radiolabeled organism-specific antibodies for imaging of infections (reviewed in 7) provides encouragement for feasibility of therapeutically targeting microbes with labeled antibodies. In fact, the ability of specific antibody to localize to a site of infection indicates the feasibility of using the antibody-antigen interaction to deliver microbicidal radiation to sites of infection, which in turn provides strong support for the potential usefulness of this technique as a broad antimicrobial strategy. Surprisingly, the concept of delivering microbicidal radiation using highly specific microbe-targeted mAbs has not attempted until very recently. In contrast, the efforts have focused on using radiolabeled antimicrobial peptides, chemotactic cytokines, leukotriene b4 antagonists, bacteriophages, chitinase, and fluconazole to distinguish sterile inflammation from infection and fungal infections which are notoriously difficult to diagnose - from bacterial infections (8-13). In addition, the use of Fanolesomab (NeutroSpec), a murine IgM monoclonal antibody to CD15 labeled with ${ }^{99 \mathrm{~m}} \mathrm{Tc}$ that co-localizes with human polymorphonuclear neutrophils (PMNs) at the sites of infection was evaluated in healthy volunteers and in patients for imaging of infection and inflammation $(14,15)$. Here we will present the summary of the therapeutic efficacy of RIT of infections, its toxicity and radiobiological mechanisms as well as will outline future perspective for combining RIT of infections with modern imaging techniques such as SPECT and PET.

\section{EFFICACY OF RIT OF INFECTIONS}

\section{RIT of fungal infections}

We initially explored the potential efficacy of RIT against an experimental fungal infection using Cryptococcus neoformans $(\mathrm{CN})(2)$. CN is a major fungal pathogen that causes lifethreatening meningoencephalitis in 6-8\% of patients with AIDS. Cryptococcal infections in immunocompromised patients are often incurable because antifungal drugs do not eradicate the infection in the setting of severe immune dysfunction $(16,17)$. CN provided a good system to study the potential usefulness of RIT because there are excellent animal models available, well characterized mAbs to $\mathrm{CN}$ antigens exist, and immunotherapy of $\mathrm{CN}$ infection with capsule polysaccharide-binding antibody 18B7 is already in clinical evaluation (18). Therapeutic studies employed AJ/Cr mice infected systemically with CN. Mice treated with radiolabeled $\mathrm{CN}$-specific $\mathrm{mAb} 18 \mathrm{~B} 7$ lived significantly longer than mice given irrelevant labeled IgG1 or PBS. We used a labeled irrelevant mAb $\left({ }^{213} \mathrm{Bi}\right.$ - or ${ }^{188} \mathrm{Re}-$ labeled $\mathrm{IgG}_{1}$ MOPC21) to control for the possibility that $\mathrm{Fc}$ receptor binding by the radiolabeled IgG to phagocytes at the site of infection might result in non-specific killing of $\mathrm{CN}$ cells. Remarkably, $60 \%$ of mice in ${ }^{213} \mathrm{Bi}$ group were alive after treatment with $100 \mu \mathrm{Ci}(3.7 \mathrm{MBq}){ }^{213} \mathrm{Bi}-18 \mathrm{~B} 7$ on day 75 after therapy $(\mathrm{P}<0.05)$. In the ${ }^{188}$ Re group $40 \%$ and $20 \%$ of animals were alive after treatment with $100(3.7 \mathrm{MBq})(\mathrm{P}<0.005)$ and $50 \mu \mathrm{Ci}(1.85 \mathrm{MBq})(\mathrm{P}<0.05){ }^{188} \mathrm{Re}-18 \mathrm{~B} 7$, respectively, while mice in control groups succumbed to infection on day 35-40 (Fig. 1a). Mice infected with $\mathrm{CN}$ and given RIT had significantly reduced fungal burden in lungs and brains $48 \mathrm{~h}$ after treatment when compared to control groups. While there was no difference in the reduction of the fungal burden in the lungs between the groups that received 50 and 100 $\mu \mathrm{Ci}{ }^{188} \mathrm{Re}-18 \mathrm{~B} 7$ (1.85 and 3.7 MBq, respectively), treatment with $200 \mu \mathrm{Ci}{ }^{188} \mathrm{Re}-18 \mathrm{~B} 7$ (7.4 $\mathrm{MBq})$ significantly lowered lung CFUs relative to the lower activities $(\mathrm{P}<0.05)$. Hence, 
administration of a radiolabeled antibody to $\mathrm{CN}$ polysaccharide prolonged survival and reduced organ fungal burden in infected mice.

When RIT dose dependence was investigated, survival of $\mathrm{A} / \mathrm{JCr}$ mice was dose dependent for both ${ }^{213} \mathrm{Bi}$ and ${ }^{188} \mathrm{Re}$ radioisotopes: while $50 \mu \mathrm{Ci}(1.85 \mathrm{MBq}){ }^{213} \mathrm{Bi}-18 \mathrm{~B} 7$ produced no therapeutic effect, both the 100 and $200 \mu \mathrm{Ci}$ (3.7 and 7.4 MBq, respectively) doses prolonged animal survival. Interestingly, the $200 \mu \mathrm{Ci}(7.4 \mathrm{MBq}){ }^{213} \mathrm{Bi}-18 \mathrm{~B} 7$ dose was less efficient, possibly because it may have approached the MTA (maximum tolerated activity) for this particular combination of antibody and radioisotope. In the ${ }^{188} \mathrm{Re}$ group, administration of 50 $\mu \mathrm{Ci}(1.85 \mathrm{MBq}){ }^{188} \mathrm{Re}-18 \mathrm{~B} 7$ resulted in some prolongation of survival, $100 \mu \mathrm{Ci}(3.7 \mathrm{MBq})$ caused significant prolongation, and $200 \mu \mathrm{Ci}(7.4 \mathrm{MBq})$ dose was, apparently, too toxic with all animals dying by day 40 .

The antimicrobial RIT approach was subsequently explored using another human pathogenic fungus, Histoplasma capsulatum (HC) (3), which is the most common cause of fungal pneumonia in immunocompromised patients (19). HC was treated in vitro with ${ }^{188} \mathrm{Re}$-labeled mAb 9C7 (IgM) which binds to a $17 \mathrm{kDa}$ protein antigen on the surface of the $\mathrm{HC}$ cell wall (20). Ninety percent of $\mathrm{HC}$ cells were killed with $32 \mu \mathrm{Ci}(1.18 \mathrm{MBq})$ of $\mathrm{HC}$-specific ${ }^{188} \mathrm{Re}-9 \mathrm{C} 7$ $\mathrm{mAb}$. In contrast, incubation of $\mathrm{HC}$ with a radiolabeled control IgM with the same specific activity produced only minimal killing within the investigated range of doses $(\mathrm{P}<0.01)$. We also performed cellular dosimetry calculations for in vitro RIT of CN and HC (3) and compared them with the $\mathrm{LD}_{90}$ for external gamma radiation. Cellular dosimetry calculations showed that RIT was $\sim 1000$-fold more efficient in killing $\mathrm{CN}$ and $\sim 100$-fold - in killing HC than gamma radiation. Thus, RIT of fungal cells using specific antibodies labeled with alpha- and betaemitting radioisotopes was significantly more efficient in killing $\mathrm{CN}$ and $\mathrm{HC}$ than gamma radiation when based on the mean absorbed dose to the cell. These results strongly support the promise of RIT as an antifungal modality.

Later we evaluated the efficacy of RIT against fungal biofilms (4). The use of indwelling medical devices - pacemakers, prosthetic joints, catheters - is rapidly growing and is often complicated by infections with biofilm-forming microbes that are resistant to antimicrobial agents and host defense mechanisms. We investigated the use of polysaccharide-specific mAbs as delivery vehicles for targeting $C$. neoformans biofilms with ${ }^{213} \mathrm{Bi} .{ }^{213} \mathrm{Bi}-18 \mathrm{~B} 7 \mathrm{mAb}(\mathrm{IgG} 1)$ penetrated cryptococcal biofilms, as shown by confocal microscopy and caused a $50 \%$ reduction in biofilm metabolic activity. In contrast, when the IgM mAb 13F1 labeled with ${ }^{213} \mathrm{Bi}$ was used - there was no penetration of the fungal biofilm and no damage. Unlabeled $18 \mathrm{~B} 7,{ }^{213} \mathrm{Bi}$-labeled non-specific mAbs, and gamma and beta types of radiation did not have an effect on biofilms. The lack of efficacy of gamma and beta radiation probably reflects the radioprotective properties of polysaccharide biofilm matrix. Our results indicate that $\mathrm{CN}$ biofilms are susceptible to treatment with antibody-targeted alpha radiation, suggesting that RIT could provide a novel option for the prevention or treatment of microbial biofilms on indwelling medical devices.

\section{RIT of bacterial infections}

Streptococcus pneumoniae (Pn), an important cause of community-acquired pneumonia, meningitis, and bacteremia, was selected for evaluating the feasibility of RIT against bacterial diseases (5). As a specific antibody carrier we utilized a human monoclonal antibody D11, which binds to pneumococcal capsular polysaccharide 8 (PPS 8), and selected a short-range alpha-emitter ${ }^{213} \mathrm{Bi}$ as the radionuclide. The experiment showed that a greater percentage of mice survived in the ${ }^{213} \mathrm{Bi}-\mathrm{D} 11$-treated group relative to the untreated group $(\mathrm{P}<0.01)$ (Fig. 1b). In contrast, administration of unlabeled D11 (5 $\mu \mathrm{g})$ did not prolong survival in comparison to untreated mice $(\mathrm{P}>0.05)$. Radiolabeled control IgM also did not have any therapeutic effect $(\mathrm{P}>0.05)$ and the survival of the mice was actually worth than in the untreated group which 
was likely due to the absence of target for the antibody to bind which resulted in excessive dose to critical blood rich organs such as bone marrow. Mice in control groups succumbed to bacteremia on Day $1-3$, while mice treated with $80 \mu \mathrm{Ci}(2.96 \mathrm{MBq}){ }^{213} \mathrm{Bi}-\mathrm{D} 11$ mice demonstrated $87-100 \%$ survival. Furthermore, mice treated with ${ }^{213} \mathrm{Bi}-\mathrm{D} 11$ were not bacteremic at 3, 6 and $10 \mathrm{~h}$ post-treatment as measured by CFU's in their blood as well as on days 3 and 14 (data not shown). Treatment with radiolabeled D11 was well tolerated - no weight loss was observed in treated animals. Thus, this study established the feasibility of RIT for the treatment of bacterial infections.

Recently we have investigated RIT of experimental Bacillus anthracis infection which is a powerful agent for bioterrorism and biological warfare underscoring the need for additional effective therapies for anthrax. Administration of ${ }^{213} \mathrm{Bi}$-labeled mAbs to anthrax toxins, namely, protective antigen and lethal factor, prolonged survival of $\mathrm{A} / \mathrm{JCr}$ mice infected with B. anthracis germinated bacterial cells (Rivera J. et al., unpublished observations).

\section{RIT of viral infections}

The HIV-1 epidemic is a major threat to global health. Highly active antiretroviral therapy (HAART), a combination of drugs that inhibits enzymes essential for HIV-1 replication, can reduce the viremia, decrease the likelihood of opportunistic infections in most patients and prolong survival. However, HAART regimens are complicated and have significant toxicity. Replication-competent virus that persists in infected cells provides a source of virus that emerges rapidly after the cessation of HAART. A modality that targets and kills HIV-1 infected cells combined with HAART would have a major impact on the treatment of acute exposure and elimination of persistent reservoirs of infected cells. We hypothesized that RIT could be potentially effective against chronically infected cells including those with viral infections (1). RIT for viral diseases would target infected cells and consequently would provide a general strategy for eliminating reservoirs of infected cells and viral cellular factories. This approach could be particularly useful for the treatment of drug-resistant HIV strains, which present an ever-increasing problem (21).

We examined the efficacy of RIT for treatment of HIV infection in vivo with a HIV envelopespecific human anti-gp41 mAb 246-D radiolabeled with ${ }^{213} \mathrm{Bi}$ or ${ }^{188} \mathrm{Re}(6)$. For these studies human peripheral blood mononuclear cells (PBMCs) infected with HIV-1 JR-CSF were injected into the spleens of SCID mice and the mice were treated IP with radiolabeled mAbs one hour later. The mice were evaluated $72 \mathrm{hr}$ later for the presence of residual HIV-1-infected cells by quantitative co-culture (22). The $72 \mathrm{hr}$ time period was chosen to allow for sufficient time for the ${ }^{188} \mathrm{Re}$-labeled $\mathrm{mAb}$ to deliver a lethal dose of radioactivity to the cells since the ${ }^{188} \mathrm{Re}$ halflife is $16.9 \mathrm{hr}$. Treatment of mice with ${ }^{188} \mathrm{Re}-$ labeled mAb 246-D administered either before or after intrasplenic injection with HIV-1 JR-CSF-infected human PBMCs dramatically reduced the number of HIV-1-infected cells (Fig. 1c). Similar results were obtained after treatment of mice with ${ }^{213} \mathrm{Bi}-246-\mathrm{D}$ (Fig. 1c). In contrast, the administration of equivalent amounts of "cold" $\mathrm{mAb} 246-\mathrm{D}$ or of a radioisotope-coupled irrelevant control $\mathrm{mAb}$ did not reduce the average number of infected cells detected in the SCID mouse spleens. ${ }^{188} \mathrm{Re}-246-\mathrm{D}$ was more effective in vivo than ${ }^{213} \mathrm{Bi}-246-\mathrm{D}$, possibly due to the longer physical half-life of ${ }^{188} \operatorname{Re}(16.9 \mathrm{~h}$ versus $46 \mathrm{~min}$ ) which allowed the labeled $\mathrm{mAb}$ to reach infected cells while still carrying high activity "payload". To investigate the dose-response effect, the mice were treated with 40, 80 and 160 $\mu \mathrm{Ci}\left(1.48,2.96\right.$ and $5.92 \mathrm{MBq}$, respectively) ${ }^{188} \mathrm{Re}-246-\mathrm{D}$, corresponding to 50,100 and $200 \%$ of the therapeutic dose, respectively. While $40 \mu \mathrm{Ci}(1.48 \mathrm{MBq}){ }^{188} \mathrm{Re}-246-\mathrm{D}$ was not effective in killing infected PBMCs in vivo, $160 \mu \mathrm{Ci}$ (5.92 MBq) dose completely eliminated infected cells. These results established that RIT could effectively target and kill HIV-1-infected human PBMCs in vivo. The demonstration of efficacy of RIT against HIV provided a proof-of- 
principle for the concept of treating viral infections by targeting viral-infected cells and this approach could be applied to other chronic viral diseases like hepatitis C (23).

\section{TOXICITY OF RIT OF INFECTIONS}

In our studies of RIT of fungal, bacterial and viral infections we evaluated the hematological toxicity of radiolabeled antibodies in mice by platelet counts $(2,5,6,24)$. While it was known from the published data that the platelet counts nadir usually occurred 1 week after radiolabeled antibody administration to tumor-bearing mice $(25,26)$ - there was no information about possible toxic effects of RIT in infected animals. RIT produced only transient drop in platelet count on day 7 post-treatment in C57BL/6 mice infected systemically with Pn and treated with $80 \mu \mathrm{Ci}^{213} \mathrm{Bi}$-D11 mAb as well as in SCID mice given $160 \mu \mathrm{Ci}{ }^{188} \mathrm{Re}-246-\mathrm{D}$ in the RIT of HIV study with counts returning to normal by day 15 (Fig. 2a, b). Also, in the RIT of HIV study we did not observe any changes in platelet counts in mice treated with $100 \mu \mathrm{Ci}^{213} \mathrm{Bi}-246 \mathrm{D}$ $\mathrm{mAb}$ on days 4,8 and 15 post-treatment in comparison to the infected non-treated controls, with platelet counts being stable at $(1.5 \pm 0.2) \times 10^{9}$ platelet $/ \mathrm{mL}$ blood. In $\mathrm{AJ} / \mathrm{Cr}$ mice systemically infected with $\mathrm{CN}$ hematologic toxicity was transient for the doses of up to 150 $\mu \mathrm{Ci}{ }^{213} \mathrm{Bi}$ - or ${ }^{188} \mathrm{Re}$-labeled mAbs (Fig. $2 \mathrm{c}$ ).

We also considered the possibility that RIT of CN infection may promote lung fibrosis in treated animals. Lungs are the target organ for $\mathrm{CN}$ infection and it is known from cancer field that lungs can develop fibrosis several months after treatment with external beam radiation therapy (27). To evaluate this potential complication we used a pulmonary model of $\mathrm{CN}$ where mice are infected intratracheally (IT). In this model, $\mathrm{CN}$ is mostly localized to the lungs on day 5 post-infection, and as a result up 10\% of the injected dose/g is found in the lungs at $24 \mathrm{~h}$ after treatment with radiolabeled MAbs, versus $1.5 \%$ of the injected dose/g in the lungs of systemically infected mice (2). BALB/c mice were infected IT with $10^{6} \mathrm{CN}$ cells, and on day 5 post-infection were treated with $50-200 \mu \mathrm{Ci}{ }^{213} \mathrm{Bi}$ - or ${ }^{188} \mathrm{Re}$-labeled mAbs or left untreated. All mice were subsequently maintained on fluconazole to control infection $(10 \mathrm{mg} / \mathrm{kg}$ in their drinking water). After 5 months, the mice were sacrificed, and their lungs were removed, fixed with buffered formalin, sectioned, stained with hematoxylin and eosin, and analyzed histologically. There was no evidence of radiation fibrosis in the lungs of radiation-treated mice (Fig. 2e, f) compared to control animals (Fig. 2d). This lack of hematological and pulmonary toxicity can be explained by the very specific targeting of radiolabeled antibodies to the microbes/infected cells. In fact, one of the advantages of using RIT against infections as opposed to cancer is that, in contrast to tumor cells, cells expressing microbial antigens are antigenically very different from host tissues and thus provide the potential for exquisite specificity and low cross-reactivity. It should also be noted that in all our studies the radiolabeled $\mathrm{mAbs}$ were administered IP, and IP administration of the radiolabeled mAbs was reported to be better tolerated than IV route (28).

In addition, when using a radioactive therapy in patients there is always a concern of long-term effects such as neoplasms arising from radiation-induced mutations. However, this risk should be extremely low after short-term exposure and would likely be outweighed by the benefits of treating or preventing infections. Nevertheless, the application of RIT to infectious diseases will require optimization of the dose to ascertain and minimize toxic effects.

\section{RADIOBIOLOGICAL MECHANISMS OF RIT OF INFECTIONS}

Given that RIT of infectious diseases is a relatively young field, the mechanisms by which RIT is effective are uncertain. Even in oncology where the anti-neoplastic effects of RIT have been investigated for more than 25 years the cytotoxic mechanisms are still debated. The major radiobiological mechanisms of cancer RIT are considered to be "direct hit" and "cross-fire" effects, both of which can promote apoptosis and cell cycle redistribution (29). We investigated 
the radiofungicidal effects of external gamma radiation and ${ }^{213} \mathrm{Bi}$ - or ${ }^{188} \mathrm{Re}-$ labeled $\mathrm{mAbs}$ on $\mathrm{CN}$ cells by evaluating the effect of radiofungicidal doses on cell membrane permeability, induction of apoptosis, and cellular metabolism (30).

An increased membrane permeability to the dye propidium iodide (PI) which is excluded from cells with intact membranes is considered to be a marker of cell death. Internalized PI binds to nucleic acids and undergoes a large increase in fluorescence (31). PI staining correlates with loss of colony forming units (CFUs) in a variety of microorganisms including $\mathrm{CN}$ treated with antifungal agents (32). More than $95 \%$ of heat killed CN cells were PI positive and served as positive control while untreated $\mathrm{CN}$ cells were negative controls. Cells stained with PI immediately or $1 \mathrm{hr}$ following gamma irradiation showed no uptake of PI (not shown). The permeability increased with time between 1 and $3 \mathrm{hr}$ following gamma irradiation, indicating that it was probably secondary to cell death, not a cause of death (Fig. 3a). It seems likely that the cells in this $20 \%$ of the population are metabolically "dead" and unable to maintain membrane integrity. Cells stained $3 \mathrm{hr}$ after irradiation showed dose dependent PI staining up $300 \mathrm{~Gy}$ (25\% PI positive), with a decrease to $10 \%$ PI positive at the highest dose (Fig 3a). This observation suggests that membrane damage is not the primary lethal event, as $80 \%$ of the cells had lost clonogenic ability at these doses. The decrease in PI positive cells at the highest dose may be due to radioprotective effects from the shed capsule (33). Treatment of $\mathrm{CN}$ with ${ }^{188} \mathrm{Re}-18 \mathrm{~B} 7$ did not make the cells PI permeable (Fig. 3b). Treatment with ${ }^{213} \mathrm{Bi}-18 \mathrm{~B} 7$ $\mathrm{mAb}$ led to about $7 \%$ of the cells becoming PI permeable, at a dose that caused $80 \%$ loss of CFUs (Fig. 3c). Higher doses of ${ }^{213} \mathrm{Bi}-18 \mathrm{~B} 7 \mathrm{mAb}$ actually decreased the permeability.

Fungal cells undergo apoptosis, or programmed cell death (34). We investigated whether radiation increased levels of fungal caspase, as measured by FLICA (fluorochrome labeled inhibitor of caspase) binding - a membrane permeable substrate that binds to caspases induced during early apoptosis. Earlier, we validated this technique for use with $\mathrm{CN}$ by comparing the FLICA results with those obtained using APO-BrdU TUNEL apoptosis detection kit (35).

Gamma irradiated cells were about 10\% FLICA positive at $3 \mathrm{hr}$ (Fig. 3d) while 20 and 5\% of $\mathrm{CN}$ cells exposed to ${ }^{188} \mathrm{Re}-18 \mathrm{~B} 7$ or ${ }^{213} \mathrm{Bi}-18 \mathrm{~B} 7 \mathrm{mAbs}$, respectively, became FLICA positive (Fig. 3e,f). The number of FLICA positive ${ }^{213} \mathrm{Bi}-18 \mathrm{~B} 7 \mathrm{mAb}$-treated cells staining was higher at $17 \mathrm{hrs}$ than at $3 \mathrm{hrs}$, indicating an ongoing process of apoptosis induction. Apoptosis is a dynamic process, and cells pass through several stages, not staying at any one stage for a long time. The decrease seen at $21 \mathrm{hrs}$ for the gamma-radiation treated cells may indicate that at 21 hrs the cells have finished the stage of apoptosis during which the caspases are available to bind the fluorescent inhibitors. This is in contrast to the increase with time observed for ${ }^{213} \mathrm{Bi}-18 \mathrm{~B} 7 \mathrm{mAb}$ treated cells, and may reflect a difference in pathways of cell death induced by the different forms of radioactivity. We concluded that gamma, beta and alpha radiation affected cells via different pathways. Gamma radiation had more effect on the cell membrane than ${ }^{213} \mathrm{Bi}-18 \mathrm{~B} 7$ or ${ }^{188} \mathrm{Re}-18 \mathrm{~B} 7$. All forms of radiation stimulated apoptosis-like cell death with gamma radiation and ${ }^{188} \mathrm{Re}-18 \mathrm{~B} 7 \mathrm{mAb}$ having more pronounced effect than ${ }^{213} \mathrm{Bi}-18 \mathrm{~B} 7 \mathrm{mAb} .{ }^{213} \mathrm{Bi}-18 \mathrm{~B} 7 \mathrm{mAb}$ delivered "directly" decreased the metabolic activity of fungal cells, while the other forms of radiation did not. Clonogenic survival proved to be the most practical measure of assessing RIT efficacy, by virtue of reflecting a combination of multiple mechanisms leading to fungal cell death. Cells which are alive post-RIT treatment, but not replicating, may or may not contribute to the disease.

To elucidate the contribution of "direct hit" and "cross-fire" effects to RIT of CN we compared the fungicidal activity of a mAb radiolabeled with ${ }^{213} \mathrm{Bi}$ or ${ }^{188} \mathrm{Re}$ - isotopes with different emission ranges in tissue $-50-80 \mu \mathrm{m}$ for ${ }^{213} \mathrm{Bi}$ versus $10 \mathrm{~mm}$ for ${ }^{188} \mathrm{Re}$. In cancer RIT, ${ }^{213} \mathrm{Bi}$ is assumed to kill by "direct hit", while ${ }^{188} \mathrm{Re}$ - through "cross-fire". In principle, every cell with bound radiolabeled $\mathrm{mAb}$ molecules can be killed by a "direct hit" and simultaneously serve as a source of "cross-fire" radiation. By measuring the killing of the cells in RIT and in 
"cross-fire" experiments, we can calculate contribution of "direct hit" towards cell killing by subtracting percentage of cells killed by "cross-fire" from percentage of cells killed by RIT. To observe "cross-fire" we had to ensure that the cells that served as the sources of "cross-fire" radiation could not be killed themselves by "direct hit". Consequently, we used heat killed CN cells. Experiments with ${ }^{213} \mathrm{Bi}-18 \mathrm{~B} 7$ showed that although most fungal cells were killed by "direct hit", "cross-fire" effect also contributed to the fungicidal effect of RIT (Fig. 3g). No killing of CN cells by unlabeled mAb $18 \mathrm{~B} 7$ was observed. For ${ }^{188}$ Re-18B7 "cross-fire" effect was responsible for most of $\mathrm{CN}$ killing (Fig. 3h). This system permits experiments to elucidate precise mechanisms of cell killing in RIT that have not been performed either for microbial or cancer cells. In RIT, targeting of cancer cells the antibody is often internalized after binding, adding significant complexity to the experiment. One of the advantages of the $\mathrm{CN}$ system is that the capsule is outside the cell wall and that antibody is not internalized, thus allowing exploration of this fundamental problem in radiobiology. Knowledge of the radiobiological mechanisms of RIT will allow creation of more effective protocols for RIT of opportunistic fungal infections.

\section{CONCLUSIONS}

As microbial cells are foreign to the human body - they contain antigens that are not expressed by human tissues and this provide a major contrast to cancer RIT since tumor-associated antigens are also expressed on normal tissues. Consequently, the theoretical therapeutic index of RIT for microbial diseases should be significantly higher than for neoplastic diseases. This exquisite specificity promises exclusivity of targeting which should translate into high efficacy of treatment and low toxicity. In cancer RIT often the matching pairs of radionuclides are used for imaging of the disease followed by therapy with the example being ${ }^{111} \mathrm{In}-{ }^{90} \mathrm{Y}$ matching pair of radionuclides utilized in Zevalin® regimen. Likewise, we envision that first the organism-specific mAbs will be radiolabeled with imaging radionuclides such as ${ }^{99 \mathrm{~m}} \mathrm{Tc}$ or ${ }^{111}$ In to localize the sites of infection with SPECT followed by RIT with ${ }^{188} \mathrm{Re}$ - or ${ }^{90} \mathrm{Y}$ labeled $\mathrm{mAb}$, respectively. Also, immunoPET might be utilized for imaging of infection before treatment if such positron-emitting radionuclides as ${ }^{86} \mathrm{Y}$ (matching pair for ${ }^{90} \mathrm{Y}$ ) or ${ }^{124} \mathrm{I}$ (matching pair for ${ }^{131}$ I) are available. It might be possible to create a so-called "pan-antibody" which would recognize an antigen shared by a particular class of human pathogens such as fungi, for example. An example of such "pan-antibody" is a mAb 6D2 initially developed against fungal melanin which also binds to synthetic, invertebrate (cuttlefish), murine and human melanins (36). The availability of such antibodies would eliminate the necessity of having antibodies specific for each particular microorganism and would enormously enhance the development of RIT of infectious diseases.

\section{Acknowledgements}

E. Dadachova is supported by the National Institute of Allergy and Infectious Disease (NIAID) grant AI60507; A. Casadevall - by NIAID grants AI033142 and AI033774.

\section{References}

1. Casadevall A, Dadachova E, Pirofski L. Passive antibody therapy for infectious diseases. Nat Rev Microbiol 2004;2:695-703. [PubMed: 15372080]

2. Dadachova E, Nakouzi A, Bryan R, et al. Ionizing radiation delivered by specific antibody is therapeutic against a fungal infection. Proc Natl Acad Sci U S A 2003;100:10942-10947. [PubMed: 12930899]

3. Dadachova E, Howell RW, Bryan RA, et al. Susceptibility of human pathogens Cryptococcus neoformans and Histoplasma capsulatum to gamma radiation versus radioimmunotherapy with alphaand beta-emitting radioisotopes. J Nucl Med 2004;45:313-320. [PubMed: 14960655]

4. Martinez LR, Bryan RA, Apostolidis C, et al. Antibody-guided alpha-radiation effectively damages fungal biofilms. Antimicrob Agents Chemother 2006;50:2132-2136. [PubMed: 16723575] 
5. Dadachova E, Burns T, Bryan RA, et al. Feasibility of radioimmunotherapy of experimental pneumococcal infection. Antimicrob Agents Chemother 2004;48:1624-1629. [PubMed: 15105113]

6. Dadachova E, Patel MC, Toussi S, et al. Targeted killing of virally infected cells by radiolabeled antibodies to viral proteins. PLoS Medicine 2006;3:e427. [PubMed: 17090209]

7. Dadachova E, Casadevall A. Antibodies as delivery vehicles for radioimmunotherapy of infectious diseases. Expert Opinion Drug Deliv 2005;2:1075-1084.

8. van Eerd JE, Oyen WJ, Harris TD, et al. Scintigraphic imaging of infectious foci with an 111In-LTB4 antagonist is based on in vivo labeling of granulocytes. J Nucl Med 2005;46:786-793. [PubMed: 15872352]

9. van Eerd JE, Rennen HJ, Oyen WJ, et al. Scintigraphic detection of pulmonary aspergillosis in rabbits with a radiolabeled leukotriene b4 antagonist. J Nucl Med 2004;45:1747-1753. [PubMed: 15471844]

10. Rusckowski M, Gupta S, Liu G, et al. Investigations of a 99mTc-labeled bacteriophage as a potential infection-specific imaging agent. J Nucl Med 2004;45:1201-1208. [PubMed: 15235067]

11. Siaens R, Eijsink VG, Dierckx R, et al. 123I-Labeled chitinase as specific radioligand for in vivo detection of fungal infections in mice. J Nucl Med 2004;45:1209-1216. [PubMed: 15235068]

12. Lupetti A, Welling MM, Mazzi U, et al. Technetium-99m labelled fluconazole and antimicrobial peptides for imaging of Candida albicans and Aspergillus fumigatus infections. Eur J Nucl Med Mol Imaging 2002;29:674-679. [PubMed: 11976807]

13. Lupetti A, Welling MM, Pauwels EK, et al. Detection of fungal infections using radiolabeled antifungal agents. Curr Drug Targets 2005;6:945-954. [PubMed: 16375677]

14. Line BR, Breyer RJ, McElvany KD, et al. Evaluation of human anti-mouse antibody response in normal volunteers following repeated injections of fanolesomab (NeutroSpec), a murine anti-CD15 IgM monoclonal antibody for imaging infection. Nucl Med Commun 2004;25:807-811. [PubMed: 15266175]

15. Love C, Tronco GG, Palestro CJ. Imaging of infection and inflammation with 99mTc-Fanolesomab. Q J Nucl Med Mol Imaging 2006;50:113-120. [PubMed: 16770301]

16. Spitzer ED, Spitzer SG, Freundlich LF, et al. Persistence of initial infection in recurrent Cryptococcus neoformans meningitis. Lancet 1993;341:595-596. [PubMed: 8094831]

17. Currie BP, Casadevall A. Estimation of the prevalence of cryptococcal infection among patients infected with the human immunodeficiency virus in New York City. Clin Infect Dis 1994;19:1029_ 1033. [PubMed: 7888529]

18. Larsen RA, Pappas PG, Perfect J, et al. Phase I evaluation of the safety and pharmacokinetics of murine-derived anticryptococcal antibody $18 \mathrm{~B} 7$ in subjects with treated cryptococcal meningitis. Antimicrob Agents Chemotherapy 2005;49:952-958.

19. Retallack DM, Woods JP. Molecular epidemiology, pathogenesis, and genetics of the dimorphic fungus Histoplasma capsulatum. Microbes Infect 1999;1:817-825. [PubMed: 10816087]

20. Nosanchuk JD, Steenbergen JN, Shi L, et al. Antibodies to a cell surface histone-like protein protect against Histoplasma capsulatum. J Clin Invest 2003;112:1164-1175. [PubMed: 14561701]

21. Little SJ, Holte S, Routy JP, et al. Antiretroviral-drug resistance among patients recently infected with HIV. N Engl J Med 2002;347:385-394. [PubMed: 12167680]

22. Ho DD, Moudgil T, Alam M. Quantitation of human immunodeficiency virus type 1 in the blood of infected persons. N Engl J Med 1989;321:1621-1625. [PubMed: 2586564]

23. Casadevall A, Goldstein H, Dadachova E. Targeting viruses-harboring host cells with radiolabeled antibodies. Expert Opinion Biol Ther 2007;7:595-597.

24. Dadachova E, Bryan RA, Frenkel A, et al. Evaluation of acute hematological and long-term pulmonary toxicity of radioimmunotherapy of Cryptococcus neoformans infection in murine models. Antimicrob Agents Chemother 2004;48:1004-1006. [PubMed: 14982795]

25. Behr TM, Behe M, Stabin MG, et al. High-linear energy transfer (LET) alpha versus low-LET beta emitters in radioimmunotherapy of solid tumors: therapeutic efficacy and dose-limiting toxicity of 213Bi- versus 90Y-labeled CO17-1A Fab' fragments in a human colonic cancer model. Cancer Res 1999;59:2635-2643. [PubMed: 10363986]

26. Sharkey RM, Blumenthal RD, Behr TM, et al. Selection of radioimmunoconjugates for the therapy of well-established or micrometastatic colon carcinoma. Int J Cancer 1997;72:477-485. [PubMed: 9247292] 
27. Koenig TR, Munden RF, Erasmus JJ, et al. Radiation injury of the lung after three-dimensional conformal radiation therapy. Am J Roentgenol 2002;178:1383-1388. [PubMed: 12034601]

28. Milenic D, Garmestani K, Dadachova E, et al. Radioimmunotherapy of human colon carcinoma xenografts using a (213)Bi-labeled domain-deleted humanized monoclonal antibody. Cancer Biother Radiopharm 2004;19:135-147. [PubMed: 15186593]

29. Macklis RM. How and why does radioimmunotherapy works? Int J Radiation Oncology Biol Phys 2004;59:1269-1271.

30. Bryan RA, Huang X, Morgenstern A, et al. Dadachova Radio-fungicidal effects of external gamma radiation and antibody-targeted beta and alpha radiation on Cryptococcus neoformans. Antimicrob Agents Chemother 2008;52:2232-2235. [PubMed: 18378712]

31. Deere D, Shen J, Vesey G, et al. Flow cytometry and cell sorting for yeast viability assesment and cell selection. Yeast 1998;14:147-160. [PubMed: 9483803]

32. Benincasa M, Scocchi M, Pacor S, et al. Fungicidal activity of five cathelicidin peptides against clinically isolated yeasts. J Antimicrob Chemother 2006;58:950-959. [PubMed: 17023499]

33. Bryan RA, Zaragoza O, Zhang T, et al. Radiological studies reveal radial differences in the architecture of the polysaccharide capsule of Cryptococcus neoformans. Eukaryot Cell 2005;4:465-475. [PubMed: 15701808]

34. Madeo F, Herker E, Wissing S, et al. Apoptosis in yeast. Curr Opin Microbiol 2004;7:655-660. [PubMed: 15556039]

35. Dadachova E, Bryan RA, Apostolidis C, et al. Interaction of radiolabeled antibodies with fungal cells and components of immune system in vitro and during radioimmunotherapy of experimental fungal infection. J Infect Dis 2006;193:1427-1436. [PubMed: 16619191]

36. Dadachova E, Nosanchuk JD, Shi L, et al. Dead cells in melanoma tumors provide abundant antigen for targeted delivery of ionizing radiation by a monoclonal antibody to melanin. Proc Natl Acad Sci USA 2004;101:14865-14870. [PubMed: 15469923] 
a)

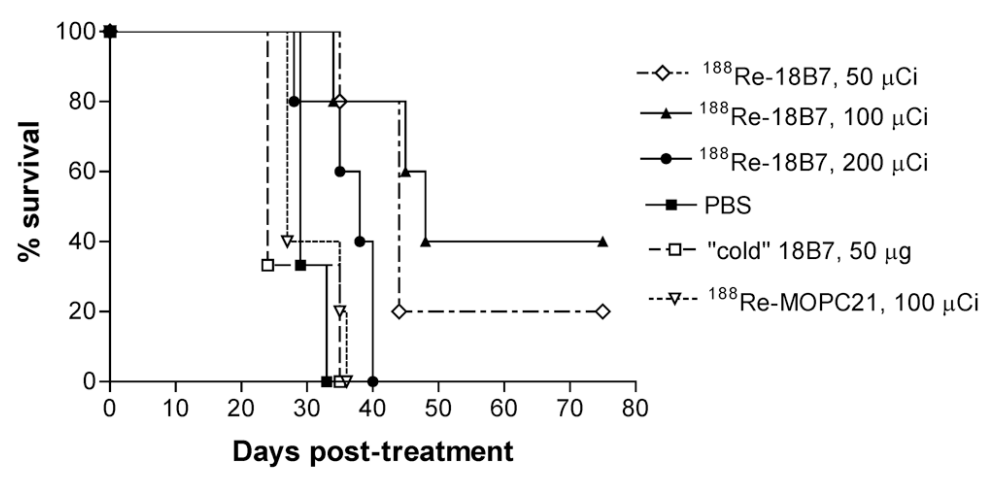

b)

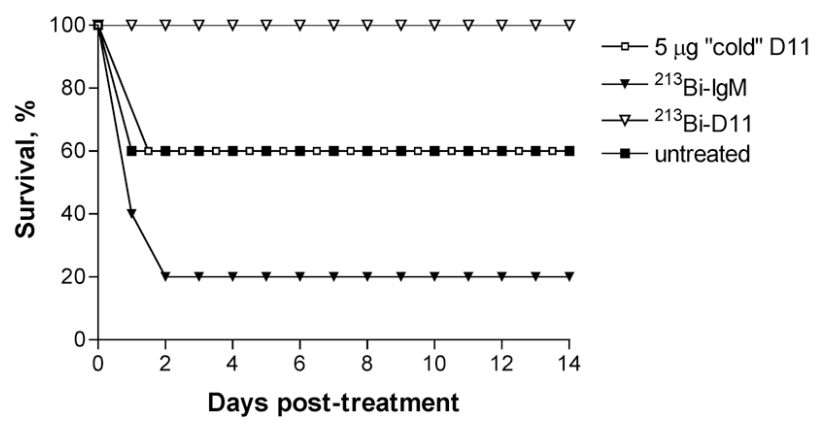

c)

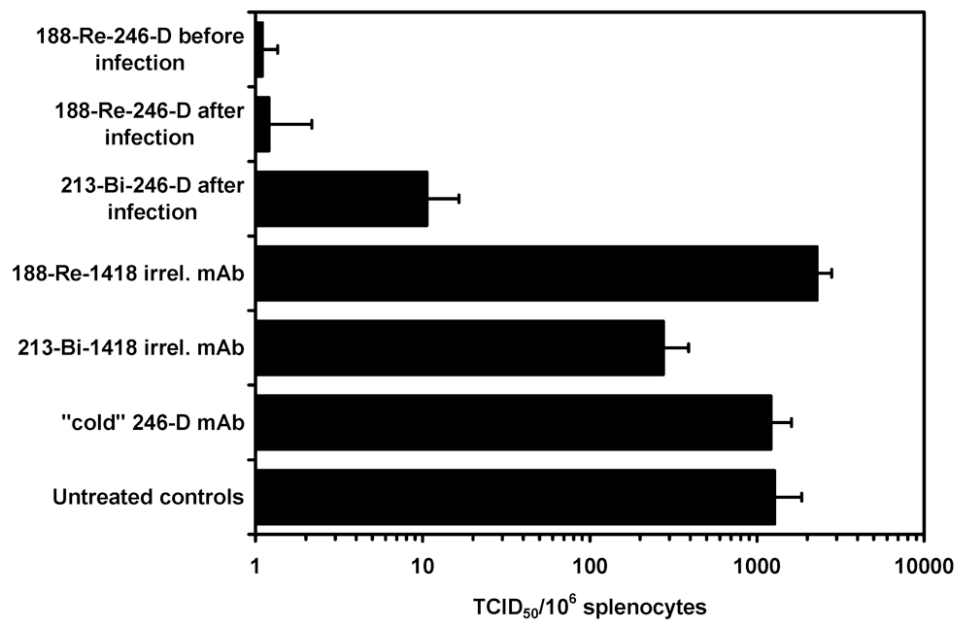

Fig. 1.

Radioimmunotherapy of experimental fungal, bacterial and viral infections with ${ }^{213} \mathrm{Bi}$ and ${ }^{188}$ Re-labeled mAbs: a) Kaplan-Meier survival curves for A/JCr mice infected IV with $10^{5} \mathrm{C}$. neoformans cells $24 \mathrm{hr}$ prior to treatment with $50-200 \mu \mathrm{Ci}{ }^{188} \mathrm{Re}$-labeled mAbs. Animals injected with PBS (phosphate buffered saline) or $50 \mu \mathrm{g}$ "cold" $18 \mathrm{~B} 7$ served as controls; b) RIT of $S$. pneumoniae infection with ${ }^{213} \mathrm{Bi}$-labeled $\mathrm{mAbs}$ in C57BL/6 mice. Mice were infected IP with 1,000 organisms $1 \mathrm{hr}$ before treatment with mAbs; c) RIT of SCID mice injected intrasplenically with JR-CSF-infected human PBMCs and treated with ${ }^{188} \mathrm{Re}$ - and ${ }^{213} \mathrm{Bi}$ labeled human anti-gp41 mAb 246-D. Mice received either $20 \mu \mathrm{g}$ "cold" anti-gp41 mAb 246$\mathrm{D}, 100 \mu \mathrm{Ci}(20 \mu \mathrm{g}){ }^{213} \mathrm{Bi}-1418$ or $80 \mu \mathrm{Ci}(20 \mu \mathrm{g}){ }^{188} \mathrm{Re}-1418$ as isotype-matching controls, 80 
$\mu \mathrm{Ci}(20 \mu \mathrm{g}){ }^{188} \mathrm{Re}-246-\mathrm{D}$, or $100 \mu \mathrm{Ci}(20 \mu \mathrm{g}){ }^{213} \mathrm{Bi}-246-\mathrm{D}$ IP 1 hour after injection of PBMCs. In some experiments mice were given $80 \mu \mathrm{Ci}(20 \mu \mathrm{g}){ }^{188} \mathrm{Re}-246-\mathrm{D}$ IP $1 \mathrm{~h}$ prior to injection of PBMCs. 
a)

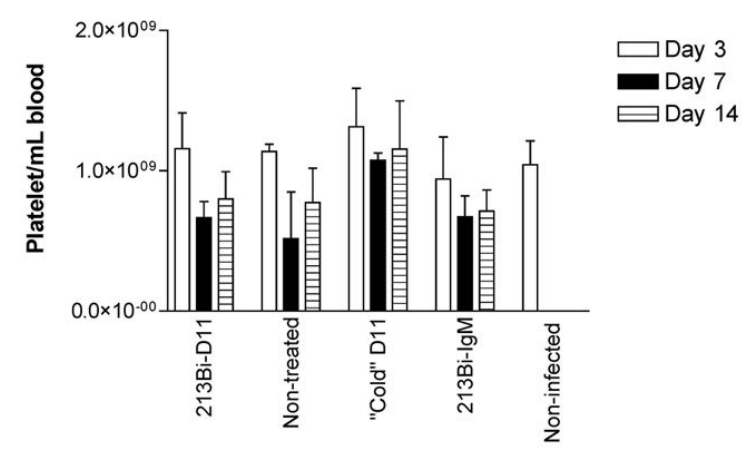

c)

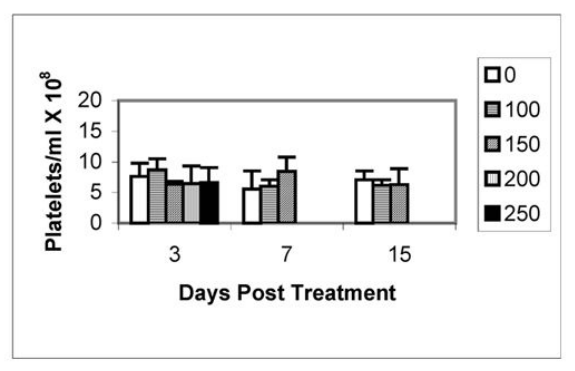

e)

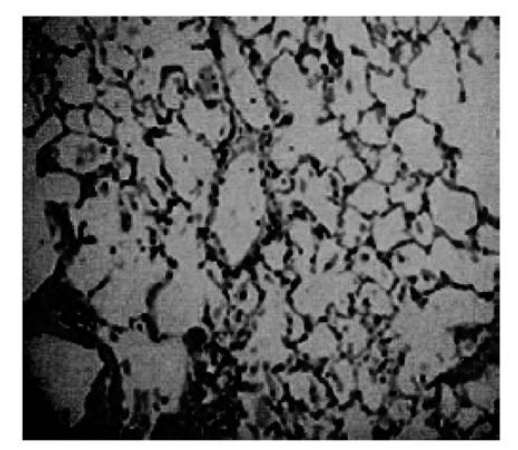

c)

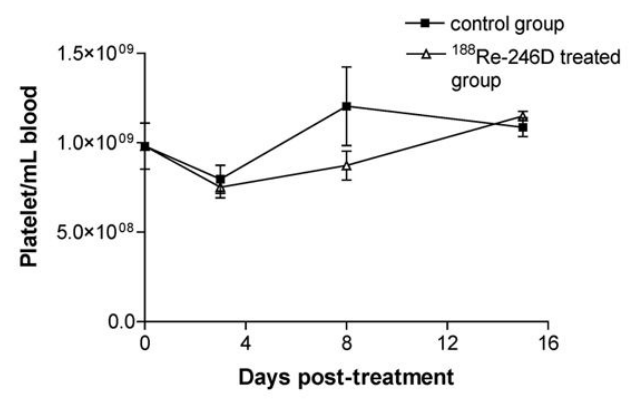

d)

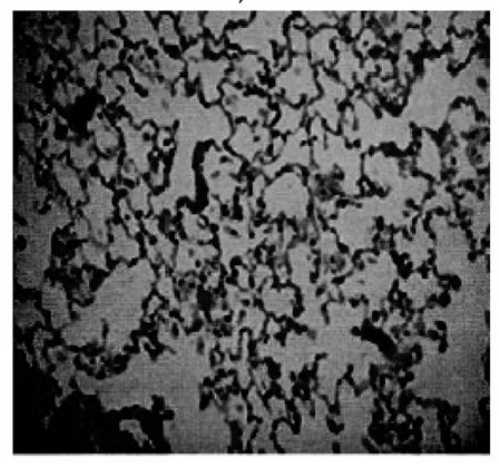

f)

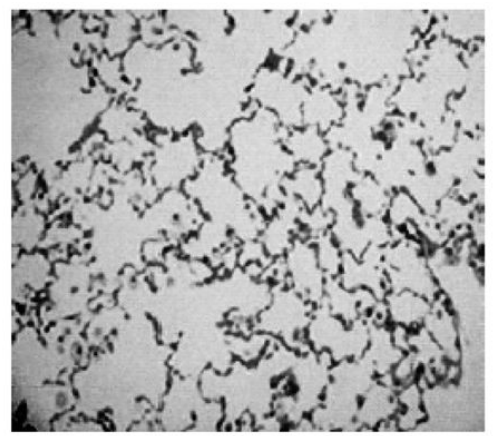

Fig. 2.

Toxicity of RIT in mice with experimental bacterial, viral and fungal infections. (a-c) Platelet counts in RIT-treated mice: a) C57BL/6 mice infected IP with Pn and treated with ${ }^{213} \mathrm{Bi}$-labeled mAb 1 h post-infection; b) SCID mice injected intrasplenically with HIV-1 infected human PBMCs and treated with ${ }^{188} \mathrm{Re}-246-\mathrm{D} \mathrm{mAb}$; c) C. neoformans-infected A/JCr mice received various doses of ${ }^{213} \mathrm{Bi}-18 \mathrm{~B} 7$. A “ 0 ” indicates infected non-treated mice. Mice treated with 200 and $250 \mu \mathrm{Ci}^{213} \mathrm{Bi}-18 \mathrm{~B} 7$ died by day 7 post-treatment. (d-f) Micrographs of hematoxylin-andeosin-stained lungs from BALB/c mice infected IT with $C$. neoformans and treated with radiolabeled $\mathrm{mAbs}$. Mice were sacrificed 5 months after RIT: d) infected control group (no RIT); e) $200 \mu \mathrm{Ci}{ }^{213} \mathrm{Bi}-18 \mathrm{~B} 7$; f) $200 \mu \mathrm{Ci}{ }^{188} \mathrm{Re}-18 \mathrm{~B} 7$. 
a)

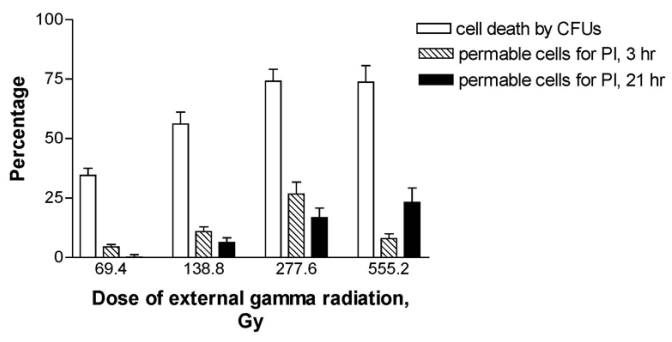

c)

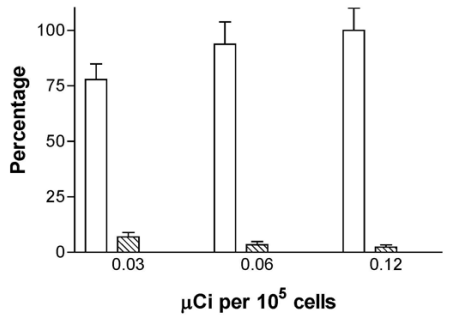

e)

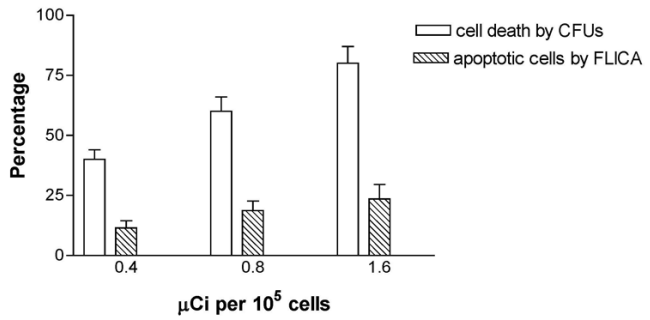

g)

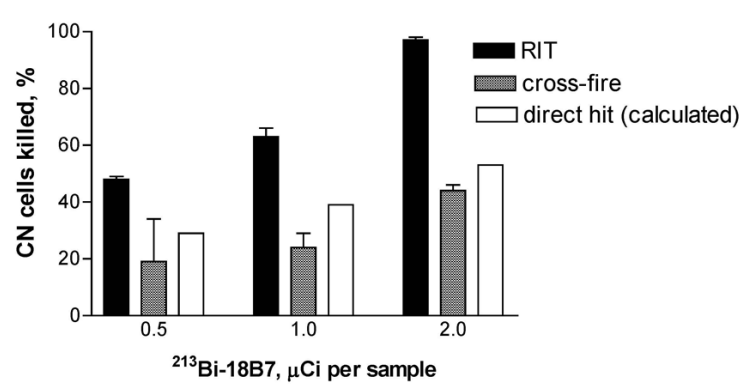

b)

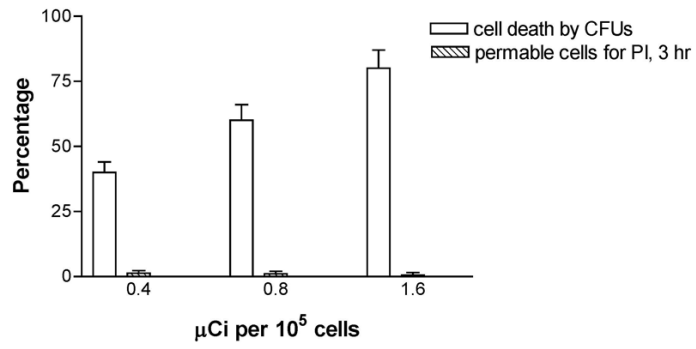

d)

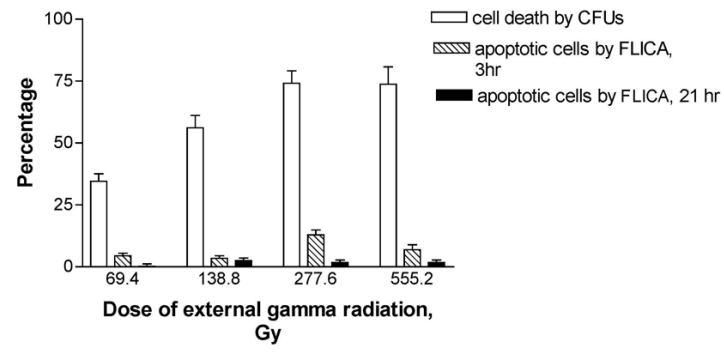

f)

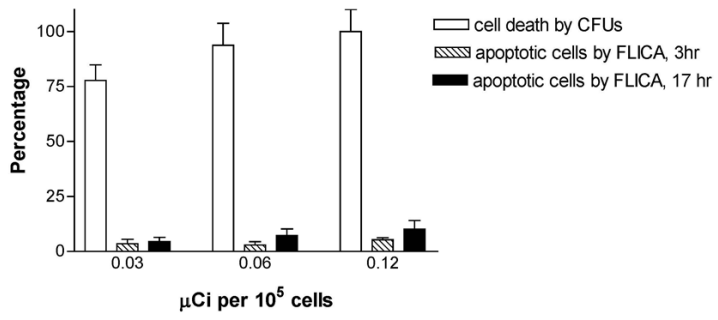

h)

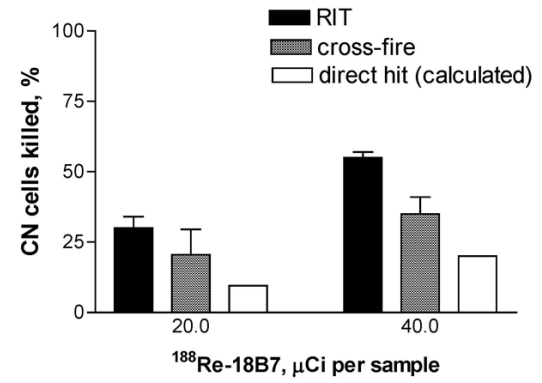

Fig. 3.

Contribution of different radiobiological effects to RIT of C. neoformans with ${ }^{213} \mathrm{Bi}-18 \mathrm{~B} 7$ and ${ }^{188} \mathrm{Re}-18 \mathrm{~B} 7 \mathrm{mAbs}$. Plates a-c show CFUs and PI permeability for: a) external gamma radiation; b) ${ }^{188} \mathrm{Re}-18 \mathrm{~B} 7$; c) ${ }^{213} \mathrm{Bi}-18 \mathrm{~B} 7$. Plates d-f show CFUs and apoptosis levels by FLICA: d) external gamma radiation; e) ${ }^{188} \mathrm{Re}-18 \mathrm{~B} 7$; f) ${ }^{213} \mathrm{Bi}-18 \mathrm{~B} 7$. Plates g-h show contribution of "cross-fire" and "direct hit" towards killing of $C$. neoformans cells: g) "cross-fire" and "direct hit" for ${ }^{213} \mathrm{Bi}-18 \mathrm{~B} 7$; h) "cross-fire" and "direct hit" for ${ }^{188} \mathrm{Re}-18 \mathrm{~B} 7$. The contribution of "direct hit" towards cell killing was calculated by subtracting percentage of cells killed by "cross-fire" from percentage of cells killed by RIT. 